Pol yneur opat hy caused by cobal t- chr om um metal I osi s after total hi $p$ repl acement

\begin{tabular}{|l|l|}
\hline 著者 & $\begin{array}{l}\text { I keda Tokuhei, Takahashi Kazuya, Kabat a Tammn, } \\
\text { Sakagoshi Dai go, Tomi t a Kat sur o, Yamada } \\
\text { Nasahi to }\end{array}$ \\
\hline $\begin{array}{l}\text { j our nal or } \\
\text { publ i cat i on t i t l e }\end{array}$ & Miscl e and Nerve \\
\hline vol une & 42 \\
\hline number & 10 \\
\hline page r ange & $140-143$ \\
\hline year & $2010-07-01$ \\
\hline URL & ht t p: //hdl . handl e. net /2297/24812 \\
\hline
\end{tabular}

doi: $10.1002 /$ mus.21638 
Case of the Month:

\section{Polyneuropathy Caused by Cobalt-Chromium Metallosis after Total}

\section{Hip Replacement}

Tokuhei Ikeda, MD, ${ }^{1 *}$ Kazuya Takahashi, MD, PhD, ${ }^{1,3}$ Tamon Kabata, MD, PhD, ${ }^{2}$ Daigo Sakagoshi, $\mathrm{MD},{ }^{2}$ Katsuro Tomita, MD, $\mathrm{PhD},{ }^{2}$ and Masahito Yamada, MD, $\mathrm{PhD}{ }^{1}$

\section{Authors' affiliations:}

${ }^{1}$ Department of Neurology and Neurobiology of Aging, Kanazawa University, Graduate School of Medical Science, 13-1 Takara-machi, Kanazawa 920-8640, Japan

${ }^{2}$ Department of Orthopedic Surgery, Kanazawa University, Graduate School of Medical Science, 13-1 Takara-machi, Kanazawa 920-8640, Japan

${ }^{3}$ Department of Neurology, lou Hospital, Ni-73-1 Iwade-machi, Kanazawa 920-0192, Japan

*Correspondence and reprint requests to: Tokuhei Ikeda 13-1 Takara-machi, Kanazawa 920-8640, Japan

Tel: +81-76-265-2292; Fax: +81-76-234-4253; E-mail: tokuhei@med.kanazawa-u.ac.jp

Running title: Co/Cr-Induced Toxic Neuropathy

Acknowledgments: We thank Mrs. Y. Kakuta and Mrs. Y. Yamaguchi for excellent technical assistance. 
Co/Cr-induced Toxic Neuropathy

\title{
Polyneuropathy Caused by Cobalt-Chromium Metallosis after Total Hip Replacement
}

\begin{abstract}
Introduction: Although metal intoxication after arthroplasty causes various symptoms, polyneuropathy has never been the focus of clinical investigations. Aim: We report a 56-year-old woman with metal neuropathy. Case report: She had metallosis after hip arthroplasty with a cobalt-chromium alloy prosthesis, and developed progressive sensory disturbance, hearing loss, and hypothyroidism. Sural nerve biopsy indicated axonopathy. After exchange arthroplasty, the blood levels of cobalt and chromium decreased and her symptoms improved. Discussion: Cobalt or chromium can cause axonopathy.
\end{abstract}

Keywords: polyneuropathy; metal intoxication; artificial hip joint; biopsy 
Co/Cr-induced Toxic Neuropathy

Recently, total arthroplasty has been widely performed and multiple problems are associated with artificial joints. ${ }^{1-7}$ One of the most severe problems is metallosis, which is chronic infiltration of metallic wear debris accompanied by reactive, chronic inflammatory changes within the periprosthetic bony and soft tissues. ${ }^{1-3}$ Wear debris causes intoxication by prosthetic metallic materials, mostly by cobalt-chromium alloy or titanium. To our knowledge, there have been few reports of cobalt or chromium intoxication causing polyneuropathy, and none of them have described polyneuropathy in sufficient detail that includes biopsy. ${ }^{4,5}$ Here, we present the case of a 56-year-old woman with a detailed analysis of polyneuropathy associated with artificial joint-related metallosis.

\section{CASE REPORT}

In June 2006, a 56-year-old woman was admitted to our hospital with progressive dysesthesia in all extremities, gait disturbance, and auditory disturbance. At 51 years of age, the patient had undergone bilateral total hip arthroplasty with a ceramic-on-ceramic bearing due to coxarthrosis. Three years later, the ceramic inner socket liner for the right hip prosthesis fractured and was replaced with a new bearing surface that had a cobalt-chromium alloy head and a polyethylene liner.

Two years after the revision surgery, the patient experienced general malaise, low-grade fever, auditory disturbance, and pain in the right hip and anterior neck. Her house doctor treated her with prednisolone and levothyroxine sodium on diagnosing acute exacerbation of chronic thyroiditis with hypothyroidism. Although her fever and neck pain improved with the treatment, numbness and tingling in the distal portions of her limbs gradually exacerbated. She eventually needed a cane to walk and was later admitted to our hospital.

On admission, physical examination indicated a normal thyroid gland and painful swelling of the right hip. Neurologically, she had painful dysesthesia and paresthesia distal to the elbows and knees, and her joint position sense was impaired in the fingers and feet. She had distal dominant 
Co/Cr-induced Toxic Neuropathy slight muscle weakness, no deep tendon reflexes, and a bilateral perceptive hearing loss. These neurological symptoms progressed after admission. She received $10 \mathrm{mg}$ of prednisolone and 50 $\mu \mathrm{g}$ of levothyroxine sodium.

Nerve conduction studies showed that sensory nerve action potentials could not be evoked in all extremities (Table 1 and Fig. 1A), but the results of motor conduction studies were normal. Pure tone audiometry showed hearing thresholds of 52 and $45 \mathrm{~dB}$ in the right and left ear, respectively (average threshold at $0.5,1,2$, and $4 \mathrm{kHz}$ ). Laboratory studies revealed mild inflammatory changes, including elevated levels of erythrocyte sedimentation rate (ESR; $59 \mathrm{~mm}$ in the first hour; normal value, $<15 \mathrm{~mm}$ ), C-reactive protein ( $0.6 \mathrm{mg} / \mathrm{dL}$; normal value, $<0.3 \mathrm{mg} / \mathrm{dL}$ ), and white blood cell count (WBC; $11.600 / \mu \mathrm{L}$; normal value, $<8.800 / \mu \mathrm{L})$. The following tests were normal or negative: renal and liver functions, glucose tolerance, autoantibodies (including antinuclear, antigangliosides, antineutrophilic cytoplasmic, antithyroid peroxidase, and antithyroglobulin antibodies), and M protein. Her thyroid function was normal under thyroid hormone replacement therapy. A cerebrospinal fluid examination showed an elevated protein level (85 mg/dL) with no pleocytosis and negative cytology. Notably, blood concentrations of cobalt ( $>400 \mu \mathrm{g} / \mathrm{L}$; normal control: $0.18 \pm 0.10 \mu \mathrm{g} / \mathrm{L})$ and chromium $(221 \mu \mathrm{g} / \mathrm{L}$; normal control: $0.28 \pm 0.12 \mu \mathrm{g} / \mathrm{L})$ were markedly elevated compared with the previous report. ${ }^{8} \mathrm{~A}$ left sural nerve biopsy showed moderate axonal degeneration with no inflammatory changes in all the sections that we prepared (Fig. 2). Cobalt and chromium concentrations in the sural nerve were also elevated; cobalt $(6.7 \mu \mathrm{g} / \mathrm{g}$; other neuropathy controls $[n=5],<3.0 \mu \mathrm{g} / \mathrm{g})$ and chromium $(3.7 \mu \mathrm{g} / \mathrm{g}$; other neuropathy controls $[n=5]$, $<3.0 \mu \mathrm{g} / \mathrm{g}$ ). An X-ray of the hip joint showed a deformity in the cobalt-chromium head of the right hip prosthesis (Fig. 3A).

We diagnosed her as having metallosis and metal intoxication, and performed a second revision surgery to remove the prosthesis. During surgery, the cobalt-chromium head was found to be deformed and metallosis had spread from the right hip joint to the thigh (Fig. 3B and C). Exchange arthroplasty was performed with a new ceramic-on-ceramic bearing prosthesis, and soft tissues 
contaminated with metal debris were removed as completely as possible. She underwent hemodiafiltration only once since she declined further therapy.

More than 2 years after the second revision surgery, her blood concentration of cobalt and chromium had gradually decreased to $39 \mu \mathrm{g} / \mathrm{L}$ and $19 \mu \mathrm{g} / \mathrm{L}$, respectively, and her symptoms (e.g., tingling, numbness, and hearing impairment) had improved, allowing her to walk without any assistance. In the nerve conduction study, sensory action nerve potentials of the median nerve could be elicited (Fig. 1B). Audiometry showed improved hearing, with a mean hearing level of 32 and $27 \mathrm{~dB}$ for the right and left ear, respectively (average threshold at 0.5, 1, 2, and $4 \mathrm{kHz}$ ). Her thyroid function had become normal without steroid or thyroid hormone preparations.

\section{DISCUSSION}

Our patient suffered from biopsy-proven sensory-dominant polyneuropathy related to metallosis from cobalt-chromium, as indicated by high cobalt and chromium concentrations in the sural nerve and blood. After the second revision surgery, the patient's blood cobalt and chromium concentrations decreased and her symptoms gradually improved. Moreover, the improvement was confirmed by electrophysiological findings.

Excess blood cobalt has been reported to cause thyroiditis and auditory disturbance that improves as blood levels decrease..$^{4,5,9}$ Intoxication with mercury, thallium, and lead are well-known causes of polyneuropathy. ${ }^{9}$ However, to our knowledge, there are only 2 case reports of polyneuropathy caused by high blood levels of cobalt and chromium, ${ }^{4,5}$ and neither of these studies include details about neurological examination, nerve biopsy, or confirmed electrophysiological improvement. In our case, both auditory and sensory disturbances improved, as described in previous reports. ${ }^{4,5}$ Visual disturbances caused by cobalt intoxication have also been reported. ${ }^{4}$ The high blood levels of cobalt or chromium may be toxic to both cranial and peripheral sensory nerves.

Patients with elevated blood concentrations of metals due to metal prostheses have been reported to be associated with a systemic immune response. ${ }^{10,11}$ However, in this case biopsy of the sural 
Co/Cr-induced Toxic Neuropathy nerve proved axonal neuropathy with no evidence of inflammation. Elevation of the CSF protein might suggest the possibility of inflammation or change of permeability of the blood-nerve barrier in the nerve roots. Ten $\mathrm{mg}$ of prednisone that she had received on admission might possibly have been related to the absence of inflammation in the biopsy.

Ceramic fragments from a fractured prosthesis that remained in the joint space damaged the new metal prosthesis, resulting in severe metallosis. ${ }^{2-5}$ The number of patients undergoing implant arthroplasty is rapidly increasing, ${ }^{6}$ and prostheses made either from cobalt-chromium or ceramics are commonly used. ${ }^{7}$ Thus, more patients may be prone to metallosis severe enough to cause polyneuropathy, as we observed in our patient. Hence, more attention should be paid to sensory impairments in patients with artificial joints. 
Co/Cr-induced Toxic Neuropathy

\section{REFERENCES}

1. Busse B, Hahn M, Niecke M, Jobke B, Puschel K, Delling G, Katzer A. Allocation of nonbirefringent wear debris: darkfield illumination associated with PIXE microanalysis reveals cobalt deposition in mineralized bone matrix adjacent to $\mathrm{CoCr}$ implants. J Biomed Mater Res A 2008;87:536-545.

2. Chang JD, Lee SS, Hur M, Seo EM, Chung YK, Lee CJ. Revision total hip arthroplasty in hip joints with metallosis: a single-center experience with 31 cases. J Arthroplasty 2005;20:568-573.

3. Matziolis G, Perka C, Disch A. Massive metallosis after revision of a fractured ceramic head onto a metal head. Arch Orthop Trauma Surg 2003;123:48-50.

4. Steens W, von Foerster G, Katzer A. Severe cobalt poisoning with loss of sight after ceramic-metal pairing in a hip--a case report. Acta Orthop 2006;77:830-832.

5. Oldenburg M, Wegner R, Baur X. Severe cobalt intoxication due to prosthesis wear in repeated total hip arthroplasty. J Arthroplasty 2009;24:825 e815-820.

6. Weng HH, Fitzgerald J. Current issues in joint replacement surgery. Curr Opin Rheumatol 2006;18:163-169.

7. Learmonth ID, Young C, Rorabeck C. The operation of the century: total hip replacement. Lancet 2007;370:1508-1519.

8. Poulsen OM, Christensen JM, Sabbioni E, Van der Venne MT. Trace element reference values in tissues from inhabitants of the European Community. V. Review of trace elements in blood, serum and urine and critical evaluation of reference values for the Danish population. Sci Total Environ 1994;141:197-215.

9. Goyer RA. Toxic effects of metal. In: Klaassen CD, Amdur MO, Doull J, editors. Toxicology: The basic science of poisons. New York: McGraw-Hill; 1996. p 691-736.

10. Hallab N, Merritt K, Jacobs JJ. Metal sensitivity in patients with orthopaedic implants. J Bone Joint Surg Am 2001;83-A:428-436. 
Co/Cr-induced Toxic Neuropathy

11. Hart AJ, Skinner JA, Winship P, Faria N, Kulinskaya E, Webster D, Muirhead-Allwood S, Aldam $\mathrm{CH}$, Anwar $\mathrm{H}$, Powell JJ. Circulating levels of cobalt and chromium from metal-on-metal hip replacement are associated with CD8+ T-cell lymphopenia. J Bone Joint Surg Br 2009;91:835-842. 
Table.1 Nerve Conduction Studies

\begin{tabular}{|c|c|c|c|c|}
\hline & & Right & Left & $\begin{array}{l}\text { Normal } \\
\text { values }\end{array}$ \\
\hline \multicolumn{5}{|l|}{ Motor nerve } \\
\hline Median & D.L. (ms) & 3.1 & 2.8 & $<4.0$ \\
\hline \multirow[t]{2}{*}{ (elbow-wrist) } & Amplitude (mV) & 12.8 & 12.3 & $>3.5$ \\
\hline & C.V. (m/s) & 47.7 & 47.9 & $>48$ \\
\hline Ulnar & D.L. (ms) & 2.9 & 2.9 & $<3.5$ \\
\hline \multirow[t]{2}{*}{ (elbow-wrist) } & Amplitude (mV) & 13.0 & 12.2 & $>2.8$ \\
\hline & C.V. (m/s) & 48.9 & 49.5 & $>50$ \\
\hline Peroneal(TA) & D.L. (ms) & 3.6 & 3.4 & $<4.8$ \\
\hline \multirow[t]{2}{*}{ (knee-ankle) } & Amplitude (mV) & 6.8 & 9.6 & $>2.0$ \\
\hline & C.V. (m/s) & 38.7 & 42.7 & $>42$ \\
\hline Tibia & D.L. (ms) & 4.2 & 4.4 & $<5.1$ \\
\hline \multirow[t]{2}{*}{ (knee-ankle) } & Amplitude (mV) & 8.0 & 12.0 & $>2.9$ \\
\hline & C.V. (m/s) & 32.5 & 36.2 & $>41$ \\
\hline
\end{tabular}

\section{Sensory nerve}

$\begin{array}{lllll}\begin{array}{l}\text { Median } \\ \text { (wrist) }\end{array} & \text { D.L. }(\mathrm{ms}) & \text { N.E. } & \text { N.E. } & <3.7 \\ & \text { Amplitude }(\mu \mathrm{V}) & & & >10 \\ \text { Ulnar } & \text { D.L. }(\mathrm{ms}) & \text { N.E. } & \text { N.E. } & <3.2 \\ \text { (wrist) } & \text { Amplitude }(\mu \mathrm{V}) & & & >8.0 \\ & & & \\ \text { Sural } & \text { D.L. }(\text { ms) } & \text { N.E. } & \text { N.E. } & <4.5 \\ & \text { Amplitude }(\mu \mathrm{V}) & & & >5.0\end{array}$

C.V.: Conduction velocity, D.L.: Distal latency, N.E.: Not elicited 
Co/Cr-induced Toxic Neuropathy

\section{Figure legends}

Figure 1. Sensory nerve conduction study. Sensory nerve action potentials (SNAPs) of the right median nerve could not be elicited by stimulating the wrist (1) or elbow (2) on admission (A). Two years after the surgery, SNAPs could be evoked (B).

Figure 2. Sural nerve biopsy. No significant inflammatory cell infiltration was observed in the nerve fascicles $(A)$ or in epineurial blood vessel $(B)$ (hematoxylin-eosin stain; scale bar $=50 \mu \mathrm{m}$ ). Several myelin ovoids (arrows) are present in this transverse nerve section with a large-fiber-predominant loss of myelinated fibers (myelinated fiber density $=4694 / \mathrm{mm}^{2}$ ) without any evidence of inflammation (toluidine blue stain; scale bar $=20 \mu \mathrm{m})(\mathrm{C})$. Teased fibers also show myelin ovoids (arrows) (scale bar $=10 \mu \mathrm{m})(\mathrm{D})$.

Figure 3. X-ray and surgery for removal of the right artificial hip joint. X-ray of the right hip joint shows an ellipsoidally deformed head dislocated from the center of the cup (arrow) and abnormal densities around the hip joint spreading to the lateral portion of the right thigh (arrow heads) (A). During surgery for removal of the right artificial hip joint, a coal tar-like fluid is obtained from the space between the right iliotibial band and lateral vastus muscle (B). The right lateral vastus muscle is discolored black (arrows) (C). 
Co/Cr-induced Toxic Neuropathy Abbreviations: Co: Cobalt; Cr: Chromium; SNAPs: Sensory nerve action potentials 


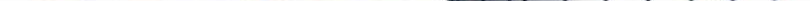


A

a. $40 \%$ $\left\{\begin{array}{l}3 \\ 3 \\ 3 \\ 3\end{array}\right.$ and

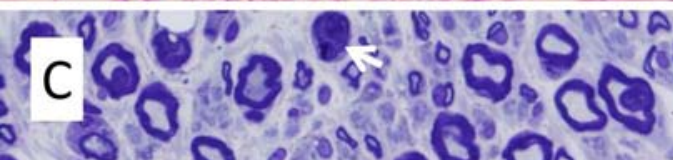
20 o $08 \%$ a sio is $50 \%$ 5. 0.5.

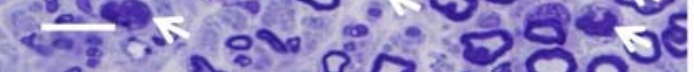
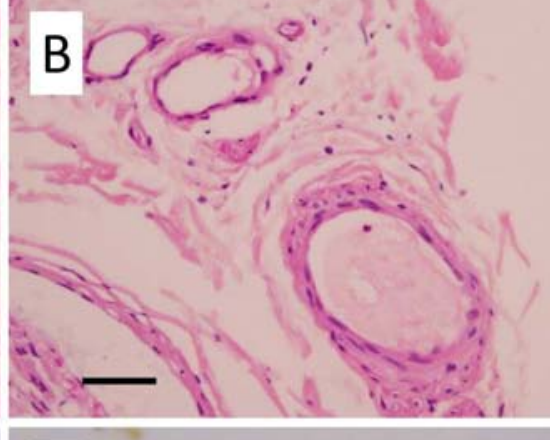


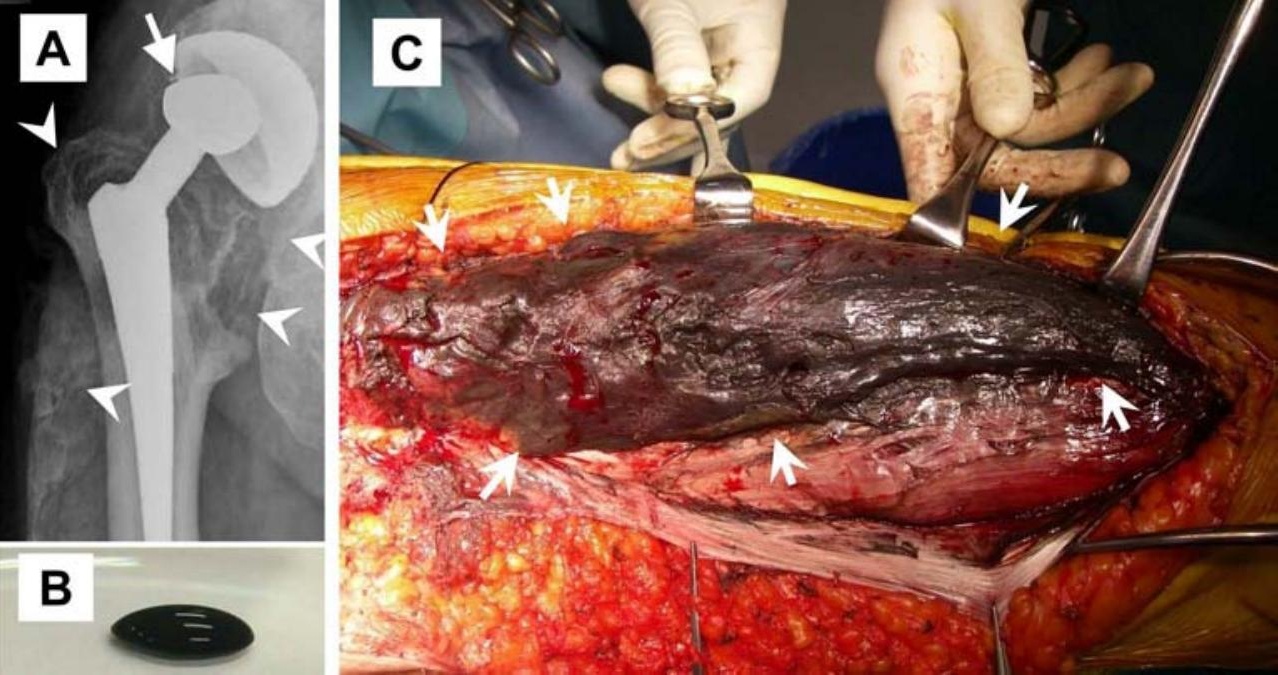

